\section{Dr. Laskari, et al reply}

\section{To the Editor:}

We appreciate the comments from Jourde-Chiche and Daugas ${ }^{1}$ on our study evaluating the frequency of renal flares in patients with proliferative lupus nephritis in whom the dose of mycophenolate mofetil (MMF) was reduced during remission maintenance therapy. They raise the question whether hydroxychloroquine (HCQ) cotreatment can influence the observed flare rates.

An association of HCQ withdrawal with exacerbations of renal disease in patients with lupus has been described by Tsakonas, et $\mathrm{al}^{2}$. Other groups, as indicated by Jourde-Chiche and Daugas, have suggested that HCQ may be protective against renal damage ${ }^{3,4}$ and increase the rates of complete remission in cases of membranous nephritis ${ }^{5}$.

We agree that HCQ may affect the outcome of renal disease. In our study, a relatively low number of patients received HCQ (7 out of 44 patients; $16 \%$ ). It was possible to reduce the dose of MMF in 2 of the 7 patients receiving HCQ, more than 18 months after remission, while 5 continued taking a stable dose of MMF until the end of followup. HCQ was used as therapy for skin and articular disease. None of the patients discontinued HCQ treatment before the end of followup. When the effect of HCQ therapy on renal relapse was calculated, statistically significant results were seen (none of the 7 patients relapsed; $p=0.037$, chi-square test). However, we emphasize that, in our study, the therapeutic use of HCQ did not differ significantly between the 2 groups of patients, that is, those who tapered MMF (group I) and those on a stable dose of MMF (Group II; $p=$ $0.682)$.

It is notable that all 7 patients receiving HCQ achieved complete renal remission. However, no significant association was demonstrated between HCQ therapy and complete renal remission $(\mathrm{p}=0.163)$. Moreover, the rates of complete resolution of renal disease activity were comparable between the 2 groups of MMF therapy ( $\mathrm{p}=0.506$ ), and no significant association was demonstrated between the achievement of complete renal remission and renal relapse in the study (HR $0.85, p=0.775$ ). However, the small number of patients did not allow solid conclusions.
These findings together point toward a potential role of HCQ in reducing renal disease activity in cases of proliferative lupus nephritis. However, they do not influence the conclusions of our study.

KATERINA LASKARI, MD; ATHANASIOS G. TZIOUFAS, MD, Professor, Department of Pathophysiology; HARALAMPOS M. MOUTSOPOULOS, MD, FRCP, FACP, MACR, Professor, Department of Pathophysiology, School of Medicine, University of Athens, Mikras Asias Street 75, Goudi 11527, Athens, Greece. Address correspondence to Dr. Laskari; E-mail: katerina_laskari@yahoo.gr

\section{REFERENCES}

1. Jourde-Chiche N, Daugas E. Longterm followup after tapering mycophenolate mofetil during maintenance treatment for proliferative lupus nephritis. J Rheumatol 2011;38:2490.

2. Tsakonas E, Joseph L, Esdaile JM, Choquette D, Senécal JL, Cividino A, et al. A long-term study of hydroxychloroquine withdrawal on exacerbations in systemic lupus erythematosus. The Canadian Hydroxychloroquine Study Group. Lupus 1998;7:80-5.

3. Pons-Estel GJ, Alarcón GS, McGwin G Jr, Danila MI, Zhang J, Bastian HM, et al; LUMINA Study Group. Protective effect of hydroxychloroquine on renal damage in patients with lupus nephritis: LXV, data from a multiethnic US cohort. Arthritis Rheum 2009;61:830-9.

4. Sisó A, Ramos-Casals M, Bové A, Brito-Zerón P, Soria N, Muñoz $\mathrm{S}$, et al. Previous antimalarial therapy in patients diagnosed with lupus nephritis: influence on outcomes and survival. Lupus 2008;17:281-8.

5. Kasitanon N, Fine DM, Haas M, Magder LS, Petri M. Hydroxychloroquine use predicts complete renal remission within 12 months among patients treated with mycophenolate mofetil therapy for membranous lupus nephritis. Lupus 2006;15:366-70.

J Rheumatol 2011;38:11; doi:10.3899/jrheum.110824 